\title{
The Impact of Ramadan Fasting on SIRT1 mRNA Expression in Peripheral Blood Mononuclear Cells
}

\author{
Mostafa Haji Molahoseini ${ }^{1}$, Kanaan Gorjipour ${ }^{1}$, Farshid Yeganeh ${ }^{* 1}$ \\ ${ }^{1}$ Department of Immunology, School of Medicine, Shahid Beheshti University of Medical Sciences, Tehran, Iran.
}

Received: 12 Apr 2016

Revised : 18 May 2016

Accepted: 7 Jun 2016

Corresponding Author Farshid Yeganeh

Department of Immunology

Faculty of Medicine Shahid Beheshti

University of Medical Sciences.

Koodakyar St;Velenjak, Tehran-Iran

Tel/Fax: +98-2122439970

E-mail: fyeganeh@sbmu.ac.ir

\begin{abstract}
Background: The aim of this study was to evaluate the effect of Ramadan fasting on SIRT1 mRNA expression in healthy men.

Islamic Ramadan fasting is a holy religious ceremony that has many spiritual benefits. Additionally, it can be considered as the equivalent of calorie restriction that may affect physical health. The results of previous studies revealed that calorie restriction increases the lifespan in laboratory rodents via increasing the expression of a histone deacetylase named SIRT1. Additionally, SIRT1 is known for its anti-inflammatory properties.

Materials and Methods: Overall, 43 men volunteered for participating in this one-group before and after (self-controlled) study. Two $\mathrm{mL}$ blood samples were taken prior to fasting and at the end of the $30^{\text {th }}$ day of fasting. Routine biochemical tests and SIRT1 mRNA expression analysis were performed.

Results: Cholesterol and low-density lipoproteins increase, however, high-density lipoproteins level decreased after Ramadan fasting. The analysis of real-time PCR results revealed that SIRT1 mRNA expression in human peripheral blood mononuclear cells increased 4.63 fold in fasting state in comparison with nonfasting state.

Conclusion: Ramadan fasting has a significant effect on SIRT1 gene expression. Considering the immunosuppressive and anti-inflammatory properties of SIRT1, further studies are needed to evaluate the effects of SIRT1 up-regulation on the autoimmune and inflammatory diseases during Ramadan fasting.
\end{abstract}

Keywords: Calorie restriction; Ramadan fasting; Sirtuin

Please cite this article as: Haji Molahoseini M, Gorjipour K, Yeganeh F. The Impact of Ramadan Fasting on SIRT1 mRNA Expression in Peripheral Blood Mononuclear Cells. Res Mol Med. 2016; 4 (4): 51-55

\section{Introduction}

Islamic Ramadan Fasting is the one-month religious ceremony that adult Muslims should refrain from eating and drinking from sunrise up to sunset. While religious fasting is done primarily for spiritual purposes, it can greatly affect one's physical health. Accordingly, the biological effects of religious fasting have recently been the subject of scientific inquiry. Ramadan fasting, which is equivalent to calorie restriction, and is defined as a reduction in food intake, has been shown to increase lifespan in laboratory rodents. This increase is associated with an increase in histone deacetylase activity of the evolutionally conserved proteins named sirtuin (1-3). SIRT1 is the best-characterized and well-studied sirtuin among the seven human sirtuins. It is a nuclear/
Cytoplasmic protein that regulates many aspects of biological functions, including metabolism, apoptosis, and aging $(4,5)$. Besides the roles that SIRT1 plays as an energy regulator in response to nutrient availability, this molecule is known for its suppressing effects on the innate and adaptive immune responses $(6,7)$. In T-cell, the up-regulated SIRT1 protein antagonizes immune response through inhibition of IL-2 production, and T cell proliferation, by means of suppressing the activations of NF- $\kappa B$ and activated protein 1 (AP-1) transcription factors (8). A previous study on mice showed that after sirt1 gene deletion, T-cell immune responses are elevated and lead to the development of a lupus-like autoimmune syndrome (9). In addition, SIRT1 is also 
found to suppress innate-immune responses through opposing NF- $\mathrm{B}$-mediated inflammatory cytokine production by macrophages (6).

Taken together, these findings demonstrate that SIRT1 is a bioenergy sensor that connects metabolism to inflammation and immune responses. Thus, the present investigation was conducted to study whether Ramadan fasting improves SIRT1 expression in human peripheral blood mononuclear cells (PBMCs) in healthy, middle aged, non-obese (normal or overweight) men before and after Ramadan fasting.

\section{Materials and methods \\ Participants}

The study was designed as a one-group before and after (self-controlled) study taking place between August and July 2015.The average duration of daily fasting was $16.5 \pm 0.5$ hours. According to religious orders, women should not fast during menstrual period. Therefore, only men were included in the study. Exclusion criteria were as follows fasting less than 29 days, smoking, body mass index (BMI) above 30 , recent infection, autoimmune and allergic diseases, and cancers. In sum, 43 men volunteered to participate in the study, and underwent physical examination, then $2 \mathrm{~mL}$ blood samples were taken prior to fasting and at the end of the 30th day of fasting. The participants were fully informed about the research goals, procedure, and then signed the consent form at the onset of the study.

\section{Routine biochemical tests}

Routine biochemical tests including fasting blood sugar (FBS), blood urea, triglycerides, cholesterol, high-density lipoproteins (HDL), and low-density lipoproteins (LDL) were measured enzymatically in plasma, before and after Ramadan fasting by using Hitachi 704 analyzer.

\section{SIRT1 mRNA expression analysis}

PBMCs were isolated via centrifugation of blood using a Ficoll density gradient. Instantly after PBMCs isolation, the entire RNA was extracted using QIAamp RNA Blood Mini Kit (QIAGEN, Germany). RNAs were converted into complementary DNA (cDNA) using RevertAid First Strand cDNA Synthesis Kit (Thermo, Lithuania). The complete process was carried out according to the manufacturer's instruction in RNase-free environment.

SIRT1 mRNA expression was evaluated using SYBR-Green based real-time RT-PCR method. Exon-exon spanning primers for SIRT1 and actinbeta genes, as a normalizer, were designed using primer design software (Beacon Designer 7, USA) (Table 1).

Table 1. The sequences of primers designed to quantify the mRNA levels of SIRT1 and Actin beta in human PBMCs before and after Ramadan fasting.

\begin{tabular}{ll}
\hline Name & Sequences $\left(\mathbf{5}^{\prime}-\boldsymbol{>} \mathbf{3}^{\prime}\right)$ \\
\hline SIRT1 Forward & TAATTCCAAGTTCCATACC \\
SIRT1 Reverse & ATTCACCACCTAACCTAT \\
Actin beta -Forward & CCTGGGCATGGAGTCCTGT \\
Actin beta - Reverse & ATCTCCTTCTGCATCCTGTCG \\
\hline
\end{tabular}

Each well contained reagent for the PCR reaction, as follows: $12.5 \mu \mathrm{L}$ of RealQ PCR 2x Master Mix Green (Ampliqon, Denmark), $1 \mu \mathrm{L}$ of forward and $1 \mu \mathrm{L}$ of reverse primer $(10 \mathrm{pMol}), 6.5 \mu \mathrm{L}$ DEPC water and 2 $\mu \mathrm{L}$ of single strand cDNA $(12.5 \mathrm{ng} / \mu \mathrm{L})$ in $20 \mu \mathrm{L}$ final volume. PCR reaction was carried out on a Rotorgene Q real-time PCR (QIAGEN, Germany) using the following processes initially, holding for 15 minutes at $94^{\circ} \mathrm{C}$ followed by 40 cycles, which comprised of denaturation for 15 seconds at $95^{\circ} \mathrm{C}$, and annealing for 30 seconds at $55^{\circ} \mathrm{C}$. All the samples were analyzed in duplicates.

The relative gene expression was calculated using REST mathematical model, which includes the efficiency (E) of every PCR reaction, as follows: Ratio $=\left(\mathrm{E}_{\text {target }}\right) \Delta \mathrm{Ct}$ target (control-sample) $/\left(\mathrm{E}_{\text {ref }}\right) \Delta \mathrm{Ct}$ ref (controlsample) (10). For each gene, cDNA dilution curves were generated and used to calculate the real-time PCR efficiencies $\left[\mathrm{E}=10^{(-1 / \text { slope of dilution curve })}\right]$.

\section{Ethics Statement}

The Ethical Committee of Shahid Beheshti University of Medical Sciences, Tehran, approved the experiment.

\section{Statistical analysis}

The normal distribution of data was verified using Kolmogorov-Smirnov test. The differences in the means were determined by paired sample t-test. All statistical analyses were performed using SPSS software (version 21). The differences were considered statistically significant when $p<0.05$.

\section{Results}

The pre- and post-Ramadan weight and BMI means were not significantly different. No significant effect of Ramadan fasting on FBS, blood urea, and triglycerides, was observed either (Table 2). The results showed that the levels of cholesterol and LDL significantly increased $(p=0.001$ and $p=0.000$, respectively), however, HDL decreased after 
Ramadan fasting ( $p=0.016$, Table 2). As the result of these changes, the ratio of LDL/HDL increased

significantly after 30 days of fasting $(\mathrm{p}=0.000)$.

Table 2. The mean of white, and routine biochemical analysis in the serum of participants before and after Ramadan fasting.

\begin{tabular}{|c|c|c|c|}
\hline & \multicolumn{2}{|c|}{ Means \pm Standard Deviation } & \multirow{2}{*}{$p$ value } \\
\hline & Before fasting & After 30 days fasting & \\
\hline Age (years) & $41 / 15 \pm 13 / 6$ & & \\
\hline FBS (mg/dL) & $84.25 \pm 16.78$ & $79.85 \pm 17.92$ & 0.286 \\
\hline Weight $(\mathrm{Kg})$ & $80.3 \pm 13 / 00$ & $79.72 \pm 14.88$ & 0.14 \\
\hline Serum Urea (mg/dL) & $36.02 \pm 7.30$ & $34.22 \pm 10.00$ & 0.079 \\
\hline Triglycerides (mg/dL) & $157.125 \pm 93.07$ & $162.57 \pm 113.17$ & 0.699 \\
\hline Cholesterol (mg/dL) & $173.00 \pm 38.03$ & $192.00 \pm 46.57$ & 0.001 \\
\hline HDL (mg/dL) & $42.25 \pm 8.99$ & $39.20 \pm 9.82$ & 0.016 \\
\hline $\mathrm{LDL}$ (mg/dL) & $97.57 \pm 34.41$ & $153.00 \pm 52.18$ & 0.000 \\
\hline LDL/HDL & $2.44 \pm 1.03$ & $4.14 \pm 1.69$ & 0.000 \\
\hline
\end{tabular}

SIRT1 mRNA expression was determined in isolated PBMCs obtained before the 1st and on the 30th days of Ramadan fasting. As shown in Figure 1, SIRT1 mRNA expression in human PBMCs showed 4.63fold increase in fasting state compared with nonfasting state $(p=0.002)$.

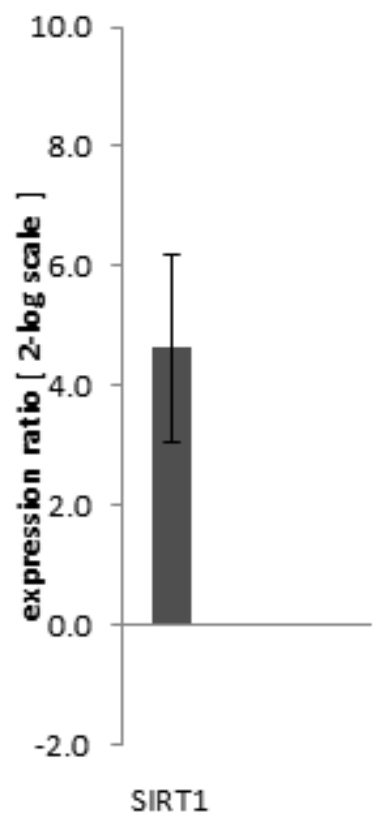

Figure 1. mRNA expression of SIRT1 in human PBMCs after Ramadan fasting. Blood samples were obtained from subjects before and after 30-day Ramadan fasting, and then the relative mRNA expression of SIRT1 was evaluated using real-time PCR. The level of SIRT1 mRNA increased 4.63 fold after Ramadan fasting.

\section{Discussion}

To address the effect of Ramadan fasting on SIRT1 gene expression in human PBMCs, we analyzed SIRT1mRNA level in the participants, before and after the 30-day fasting. The results showed that Ramadan fasting increased SIRT1 mRNA level more than four folds. It is obvious that no direct correlation exists between increase in the gene expression level and protein function. To the best of our knowledge, no study was previously conducted on the effect of Ramadan fasting on SIRT1 gene expression or protein function, although a few studies are reported investigating the effect of Ramadan fasting on inflammation and immune responses. For instance, Askari et al. showed that serum high-sensitive CRP level significantly reduced after Ramadan fasting in control and asthmatic patients (11). However, many studies highlighted the correlation between caloric restriction, SIRT1 expression, and immune responses $(6,7)$. The previous studies in rodents showed that a 24-h fasting increased mRNA and protein expression of SIRT1 in the liver (2). Additionally, scientists demonstrated that calorie restriction increases SIRT1 expression in human adipose tissue or skeletal muscle $(12,13)$. SIRT1 is an important regulator of energy homeostasis in response to nutrient availability. The results of a research on mice showed that manipulation of SIRT1 levels in the liver affects the expression of several genes which are involved in glucose and lipid metabolism (12). Moreover, SIRT1 is a critical regulator of both the innate and adaptive immune response in mice and its altered functions are 
likely involved in autoimmune diseases such as experimental autoimmune encephalomyelitis in mice $(14,15)$. SIRT1 inhibits the inflammation in the immune system via preventing $\mathrm{T}$ cell proliferation, IL17 production, Th17 differentiation, and macrophage secretory function (16). According to these findings, chemical components that reduce SIRT1 functions are considered as therapeutic reagents for autoimmune diseases (17). In addition to these small molecules, fasting is considered as a therapeutic method to resolve inflammation and reduce immune response in autoimmune diseases.

The results of this study showed that Ramadan fasting significantly increased the level of cholesterol and LDL. On the other hand, the level of HDL decreased significantly after Ramadan fasting. The alterations caused significant increase in the level of LDL/HDL ratio. Although, previous studies showed that Ramadan fasting decreases the levels of serum lipid profile, it seems that the effect of Ramadan fasting on serum lipid levels are directly influenced by the nutritional diet $(18,19)$. An increase in the ratio of $\mathrm{LDL}$ to $\mathrm{HDL}$ can increase the risk of cardiovascular disease; however, significant upregulation of SIRT1 mRNA level may decrease this risk through suppressing the inflammatory responses. Conclusion: Ramadan fasting have a considerable effect on the SIRT1 gene expression, and the previous studies have revealed that SIRT1 modulation is beneficial against several inflammatory diseases. Chronic diseases, such as obesity and diabetes might also benefit from SIRT1 targeting via Ramadan fasting, yet further investigation can shed more light on this finding.

\section{Acknowledgments}

The authors like to thank Dr. Hadi Azimi for language revision. The present article is financially supported by "Center for the Study of Religion and Health, Shahid Beheshti University of Medical Sciences," (Grant No 4552). The funders had no role in study design, data collection and analysis, decision to publish, or preparation of the manuscript. The authors certify that there is no conflict of interest in the subject matter or materials discussed in this manuscript.

\section{Authors' contributions}

HM Molahoseini participated in study designing and manuscript writing. GK took part in sample collection, and performed the experiments, and Farshid Yeganeh designed the methodology of study, as well as wrote the article.

\section{Conflict of interest}

The authors declare that they have no conflict of interest in this work.

\section{References}

1. Koubova J, Guarente L. How does calorie restriction work? Genes Dev. 2003; 17(3):313-21. PMID: 12569120

2. Cohen HY, Miller C, Bitterman KJ, Wall NR, Hekking B, Kessler B, et al. Calorie restriction promotes mammalian cell survival by inducing the SIRT1 deacetylase. Science. 2004; 305(5682):390-2. PMID: 15205477

3. Nisoli E, Tonello C, Cardile A, Cozzi V, Bracale R, Tedesco L, et al. Calorie restriction promotes mitochondrial biogenesis by inducing the expression of eNOS. Science. 2005; 310(5746):3147. PMID: 16224023

4. Bitterman KJ, Anderson RM, Cohen HY, Latorre-Esteves M, Sinclair DA. Inhibition of silencing and accelerated aging by nicotinamide, a putative negative regulator of yeast sir2 and human SIRT1. J Biol Chem. 2002; 277(47):45099-107. PMID: 12297502

5. Oberdoerffer P, Michan S, McVay M, Mostoslavsky R, Vann J, Park S-K, et al. SIRT1 redistribution on chromatin promotes genomic stability but alters gene expression during aging. Cell. 2008; 135(5):907-18. PMID: 19041753

6. Schug TT, Xu Q, Gao H, Peres-da-Silva A, Draper DW, Fessler $\mathrm{MB}$, et al. Myeloid deletion of SIRT1 induces inflammatory signaling in response to environmental stress. Mol Cell Biol. 2010; 30(19):4712-21. PMID: 20647536

7. Zhang J, Lee S-M, Shannon S, Gao B, Chen W, Chen A, et al. The type III histone deacetylase Sirtl is essential for maintenance of T cell tolerance in mice. J Clin Invest. 2009; 119(10):3048-58. PMID: 19729833

8. Gao B, Kong Q, Kemp K, Zhao Y-S, Fang D. Analysis of sirtuin 1 expression reveals a molecular explanation of IL-2-mediated reversal of T-cell tolerance. Proc Natl Acad Sci U S A. 2012; 109(3):899-904. PMID: 22219356

9. Sequeira J, Boily G, Bazinet S, Saliba S, He X, Jardine K, et al. sirt1-null mice develop an autoimmune-like condition. Exp Cell Res. 2008. 314(16):3069-74. PMID: 18687325

10. Pfaffl MW, Horgan GW, Dempfle L. Relative expression software tool (REST) for group-wise comparison and statistical analysis of relative expression results in real-time PCR. Nucleic Acids Res. 2002; 30(9):e36. PMID: 11972351

11. Askari VR, Alavinezhad A, Boskabady MH. The impact of \&quot;Ramadan fasting period\&quot; on total and differential white blood cells, haematological indices, inflammatory biomarker, respiratory symptoms and pulmonary function tests of healthy and asthmatic patients. Allergol Immunopathol (Madr). 44(4):359-67. PMID: 27040808

12. Xu C, Bai B, Fan P, Cai Y, Huang B, Law IK, et al. Selective overexpression of human SIRT1 in adipose tissue enhances energy homeostasis and prevents the deterioration of insulin sensitivity with ageing in mice. Am J Transl Res. 2013; 5(4):412-26. PMID: 23724165

13. Xu C, Cai Y, Fan P, Bai B, Chen J, Deng H-B, et al. Calorie Restriction Prevents Metabolic Aging Caused by Abnormal SIRT1 Function in Adipose Tissues. Diabetes. 2015; 64(5):1576-90. PMID: 25475438 
14. Wang J, Zhao C, Kong P, Sun H, Sun Z, Bian G, et al. Treatment with $\mathrm{NAD}(+)$ inhibited experimental autoimmune encephalomyelitis by activating AMPK/SIRT1 signaling pathway and modulating Th1/Th17 immune responses in mice. Int Immunopharmacol. 2016; 39:287-94. PMID: 27500459

15. Zhang K, Guo Y, Ge Z, Zhang Z, Da Y, Li W, et al Adiponectin Suppresses $\mathrm{T}$ Helper 17 Cell Differentiation and Limits Autoimmune CNS Inflammation via the SIRT1/PPAR $\gamma /$ ROR $\gamma$ t Pathway. Mol Neurobiol. 2016. PMID: 27514756

16. Yoshizaki T, Schenk S, Imamura T, Babendure JL, Sonoda N, Bae EJ, et al. SIRT1 inhibits inflammatory pathways in macrophages and modulates insulin sensitivity. Am J Physiol Endocrinol Metab. 2010; 298(3):E419-28. PMID: 19996381
17. Crunkhorn S. Autoimmune disease: SIRT1 inhibition suppresses multiple sclerosis. Nat Rev Drug Discov. 2015; 14(7):460. PMID: 26129800

18. Zare A, Hajhashemi M, Hassan ZM, Zarrin S, Pourpak Z, Moin $\mathrm{M}$, et al. Effect of Ramadan fasting on serum heat shock protein 70 and serum lipid profile. Singapore Med J. 2011; 52(7):491-5. PMID: 21808959

19. Afrasiabi A, Hassanzadeh S, Sattarivand R, Mahboob S. Effects of Ramadan fasting on serum lipid profiles on 2 hyperlipidemic groups with or without diet pattern. Saudi Med J. 2003; 24(1):23-6. PMID: 12590268 